\title{
Thermography Inspection of Friction Stir Welding
}

\author{
Valery E. Rubtsov ${ }^{1,2, a)}$, Evgeny A. Kolubaev ${ }^{1,3, b)}$, Sergei Yu. Tarasov ${ }^{1,3, c)}$, \\ Peter A. Vasilyev ${ }^{2, \text { d) }}$, and Vladimir A. Bakshaev ${ }^{3, \text { e) }}$ \\ ${ }^{1}$ Institute of Strength Physics and Materials Science SB RAS, Tomsk, 634055, Russia \\ 2 JSC Cheboksary Enterprise "Sespel”, Cheboksary, 428000, Russia \\ ${ }^{3}$ National Research Tomsk Polytechnic University, Tomsk, 634050, Russia

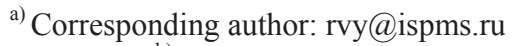 \\ b) eak@ispms.ru \\ c) tsy@ispms.ru \\ d) sespel-new@yandex.ru \\ e) zaosespel@yandex.ru
}

\begin{abstract}
The feasibility of thermography for detecting weld defects directly in the process of friction stir welding (FSW) is evaluated. Several types of temperature anomalies are revealed for friction stir welds, which are related to real seam defects, such as lack of penetration and wormholes found from the following metallographic examination.
\end{abstract}

Keywords: friction stir welding, thermography, weld defects, monitoring.

\section{INTRODUCTION}

Today, a welding technology called friction stir welding (FSW) is applied to produce aluminum alloy permanent joints in many industrial branches [1,2]. Friction stir welding has many advantages over the conventional fusion welding. It makes possible obtaining welds of great length and at a 5-10 times higher rate as compared to those obtained by gas tungsten arc welding (GTAW) methods.

In connection with the rapid development of infrared imaging equipment in recent years, thermography testing is widely applied for quality inspection of various objects along with ultrasonic, radiation and eddy current methods.

The literature provides abundant examples of using the IF cameras for the weld inspection including mainly the active control methods. However, passive thermography testing was used for the real-time monitoring of the GTAW welding process as described elsewhere $[3,4]$. The objective of this paper is to correlate the passive thermography monitoring data about temperature anomalies observed during FSW in the weld zone and defects detected in destructive testing of welds.

\section{MATERIAL AND INVESTIGATION PROCEDURE}

The FSW joining of two $5 \mathrm{~mm}$ thick plates of annealed wrought $\mathrm{Al}-5 \% \mathrm{Mg}$ alloy was carried out on a pilot plant of JSC Cheboksary Enterprise "Sespel". The weld face width was $\approx 19 \mathrm{~mm}$, and the weld length was $\approx 500 \mathrm{~mm}$. The real-time monitoring of the FSW process was carried out using a thermal imaging camera Flir A655sc operated at frame resolution $640 \times 480$ pixel and frame rate $60 \mathrm{fps}$. The camera was mounted on the FSW machine's tool head using a magnetic holder at a distance of $300 \mathrm{~mm}$ from the weld centerline; the field of vision was about $15 \mathrm{~cm}$ width. Focusing was done manually prior to welding at the weld centerline; the optical axis of the camera was inclined at an angle of $\approx 60^{\circ}$ to the workpiece plane. The camera mounted in this way moved together with the FSW machine's tool head during welding. The thermal inspection area remained stationary with respect to the welding tool while moving along the workpiece surface at the feed rate.

International Conference on Physical Mesomechanics of Multilevel Systems 2014

AIP Conf. Proc. 1623, 535-538 (2014); doi: 10.1063/1.4899000

(C) 2014 AIP Publishing LLC 978-0-7354-1260-6/\$30.00 


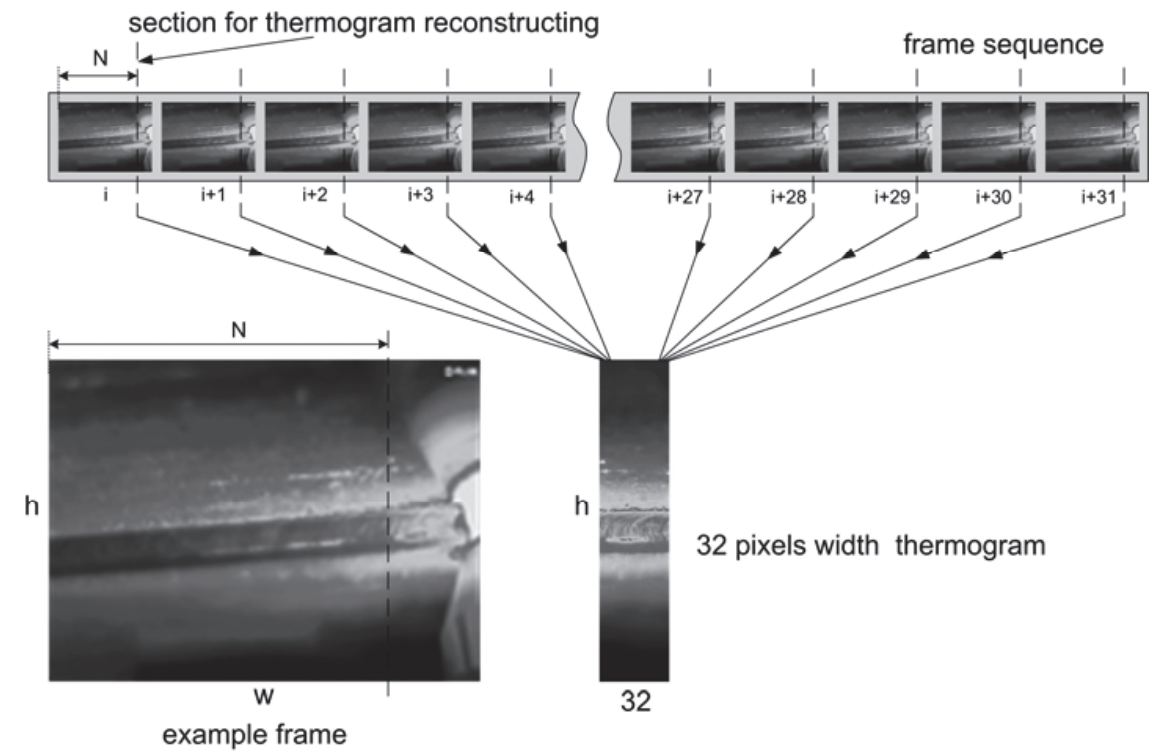

FIGURE 1. Reconstructing the thermogram from a 32 frame sequence

The recorded data were processed and a thermogram (stacked image) of the FSW process was reconstructed analogously to the method described in [4]. The thermograms obtained by the given algorithm differ from the conventional ones [5] in that they are produced for a moving, not fixed area of the workpiece surface. The scheme of reconstructing a thermogram from a 32 frames sequence is given in Fig. 1. The thermogram is an image stacked of 1 pixel wide columns extracted from frames of width $w$ and height $h$ pixels. The columns were extracted from each frame at the same distance equal to $N$ pixels from the left side of the frame.

The relation between revealed the temperature anomalies and real defects was established by metallographic analysis. Parallelepiped specimens for the analysis with a height equal to the thickness of the welded plates were cut out of the weld. Metallographic sections of the weld cut out both cross-sectionally and in a plane parallel to the weld face were examined.
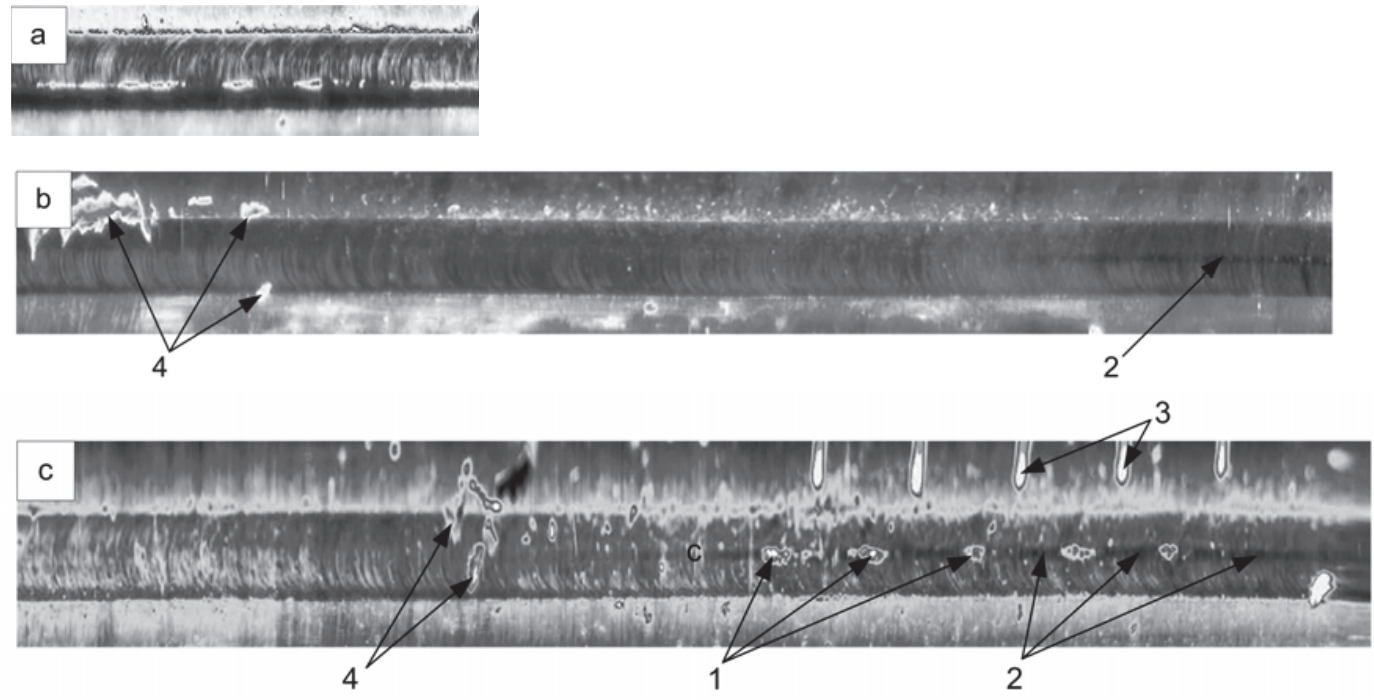

FIGURE 2. Thermogram fragments of welds produced in different welding modes 


\section{RESULTS AND DISCUSSION}

Several types of anomalies can be distinguished from the thermograms. The first type is a narrow, white or light gray, continuous, discontinuous or segmented line in the middle of the weld (designated by 1 in Fig. 2(a)). The second type is a narrow, darker than the surrounding area, line in the middle of the weld (designated by 2 in Fig. 2(b)). As a rule, this line was only observed on a part of the weld. It is clearly seen in the right part of the image in Fig. 2(b). Visual inspection revealed no anomalies on the weld face corresponding to that dark line region.

Figure 2(c) demonstrates the workpiece having both of the above-described anomalies, also designated by 1 and 2. The given workpiece had artificial defects introduced prior to welding, namely, a series of five $\varnothing 5 \mathrm{~mm}$ diameter $2.5 \mathrm{~mm}$ depth holes drilled along the in the centerline of the butt joint. The lines drawn by the marker (designated by 3 ) are clearly seen on the thermogram and designate the positions of these holes before welding. There are also five lack-of-penetration defects formed behind the holes after the passage of the tool (Fig. 2(c)). Their location corresponds exactly to the location of the lack-of-penetration defects detected by visual inspection. Between these defects, there is a well-defined darker line distinct from the surrounding area (Fig. 2(c)).

Other anomalies found are the large bright regions at the weld ends and on the weld (designated by 4 in Fig. 2(b, c)). Flash is detected in these regions by visual inspection after welding. Also the heating can be inhomogeneous along the weld, namely, temperatures in the left, central and right weld parts may be slightly different. These anomalies are probably related more to the welding rather than to the formation of defects.

The metallographic analysis of the weld cross-section in the dark line region (right part of the workpiece in Fig. 2(b)) has revealed the presence of wormhole defects $2-3 \mathrm{~mm}$ below the surface (Fig. 3(a)). The distribution of defects by depth has been obtained from a layer-by-layer metallographic analysis of in-plane weld sections. The macrograph of a section at $2.4 \mathrm{~mm}$ below the weld surface is given in Fig. 3(b) where defects formed by the rotating FSW tool are seen. The formation of wormhole defects can be considered from the viewpoint of papers [6] showing that the flow of the material in the friction zone can be accompanied by turbulence and formation of discontinuities.

Another workpiece whose thermogram shows up the dark line temperature anomaly represented (Fig. 2(c)) has a defect illustrated in Fig. 4. This defect is a group of discontinuities of various shape and size, which is asymmetric relative to the weld centerline (Fig. 4(a)). The defect is extended (Fig. 4(b)) and is located directly beneath the weld face at a depth of up to $1.5 \mathrm{~mm}$. In fact, the described defect is the lack of penetration smeared by the welding tool shoulder. This is also confirmed by its structure resembling the loose rock structure, which is found inside of visually observed lack-of-penetration defects. Despite the fact that the defect is located very close to the weld face (its minimum depth of occurrence is approximately $100 \mu \mathrm{m}$ ), it cannot be detected by visual inspection.

The structure of the defect is seen on a metallographic section parallel to the workpiece surface at a $1 \mathrm{~mm}$ depth; this structure is a group of circular segments with a spacing coinciding with the weld ripple spacing. The given defect is very dangerous as it greatly reduces the effective cross-section area of the material in the weld joint, which sustains the applied loads.

The literature reports on a very modest progress in detection and identification of weld defects by passive thermography, which mainly consists in the detection of surface defects such as lack of fusion or penetration [4]. An example of the defect is the lack of penetration detected in the present paper (bright line in Fig. 2(a)). The presence of such defects can be easily observed visually.
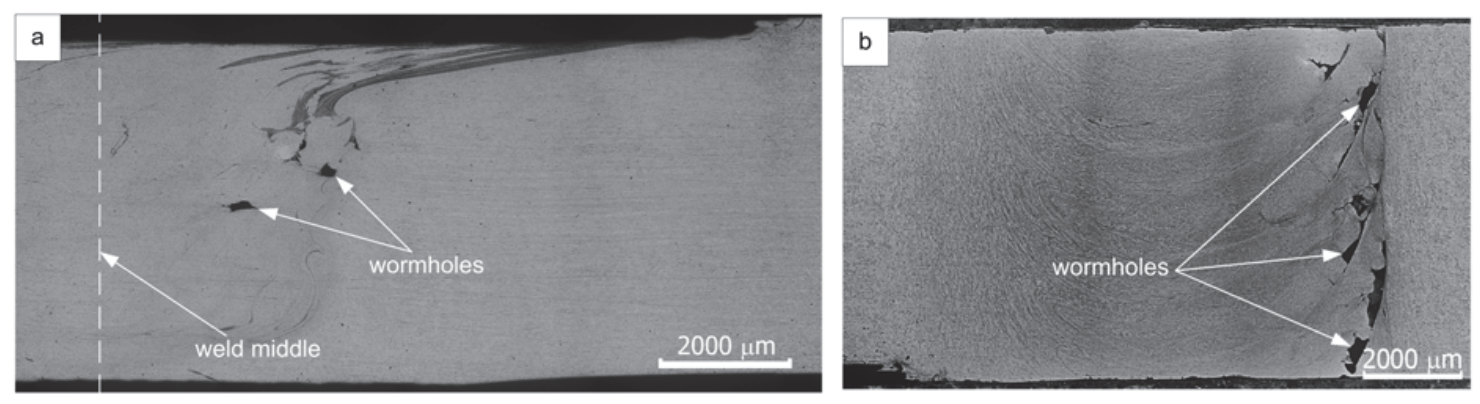

FIGURE 3. The cross-section (a) and in-plane section (b) in the dark line zone shown in Fig. 3(b) 

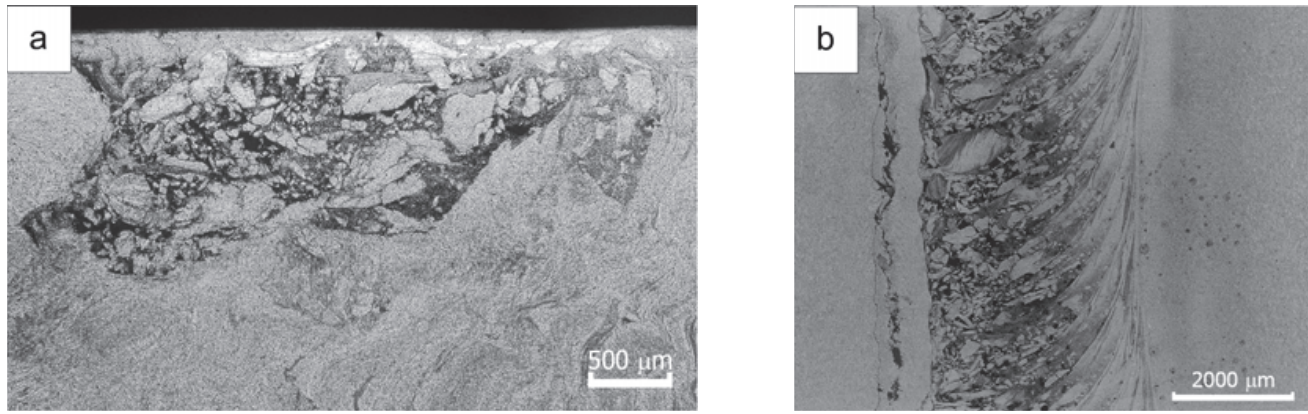

FIGURE 4. Defect represented by an extended zone of loose material corresponding to the dark line in Fig. 3(c): weld cross-section (a) and in-plane section at a $1 \mathrm{~mm}$ depth (b)

Another type of defect is the lack of penetration beneath the weld face (Fig. 2(c)), which is evidently formed due to the bad compatibility between the plate edges. The hidden lack of penetration (Fig. 2(c)) is observed on the thermogram as the dark line with decreased temperature relative to defect-free regions between the bright spots of artificially introduced defects.

According to the thermography theory [5], the wormhole defects (Fig. 3) during cooling must appear as dark regions. The temperature anomaly represented by the dark line in Fig. 2(b) is located exactly along the weld centerline, while real defects of this type are found closer to the advancing side of the weld (Fig. 3). There is a discrepancy between the location of real defects and defects detected by infrared inspection across the weld width. However, other defects are also absent in the dark line region, e.g., lack of penetration beneath the weld face (Fig. 4) which could be related to the presence of the dark line.

\section{CONCLUSION}

Analysis of temperature anomalies revealed on the workpiece surface by passive infrared inspection during FSW and their comparison to metallographic analysis data suggest that infrared inspection can be successfully applied for detecting dangerous internal defects directly in the process of welding. However, the comparison of destructive and thermography testing data cannot be interpreted unambiguously in all cases and give adequate information about a detected internal defect represented on the thermogram. In order to obtain more reliable results, it is necessary to increase the spatial resolution in thermal testing and to improve data processing techniques.

\section{ACKNOWLEDGEMENT}

The work has been supported by Project No. III.23.2.4 of SB RAS Fundamental Research Program III.23.2 and RF Ministry of Education and Science (Contract No. 02.G25.31.0063) in the framework of RF Government Order No. 218.

\section{REFERENCES}

1. R. S. Mishra and M. Mahoney, Friction Stir Welding and Processing (ASM International, 2007).

2. D. Lohwasser and Zh. Chen Woodhead (Eds.), Friction Stir Welding: From Basics to Applications (Publishing Limited and CRC Press LLC, 2010).

3. M. Vasudevan, N. Chandrasechar, V. Naduraimuthu, A. K. Bhaduri, and B. Raj, Weld. World 55(07-08), 83 (2011).

4. U. Sreedhar, C. V. Krishnamurthy, K. Balasubramaniam, V. D. Raghupathy, and S. Ravisankar, J. Mater. Process. Technol. 212, 1557 (2012).

5. V. P. Vavilov, Infrared Thermography and Thermal Nondestructive Testing (Izd. Dom "Spektr", Moscow, 2013).

6. V. E. Rubtsov, S. Yu. Tarasov, and A. V. Kolubaev, Phys. Mesomech. 15(5-6), 337 (2012). 